\title{
Selection of appropriate constraints for dimension reduction in MILD combustion simulations via RCCE
}

\author{
Chiara Galletti ${ }^{\mathrm{a}, *}$, Ben Isaac ${ }^{\mathrm{b}}$, Alessandro Parente $^{\mathrm{c}, *}$ \\ ${ }^{a}$ Universit di Pisa, Dipartimento di Ingegneria Civile e Industriale, Pisa, Italy \\ ${ }^{b}$ University of Utah, Institute of Clean $\& 5$ Secure Energy, Salt Lake City, USA \\ ${ }^{c}$ Universit Libre de Bruxelles, Ecole Polytechnique de Bruxelles, Aero-Thermo-Mechanics Laboratory, Bruxelles, Belgium
}

\begin{abstract}
Modeling MILD combustion is well known to be computationally demanding due to the need of an accurate description of the chemistry, because the low Damköhler number. The present work investigates the potentials of Rate-Controlled Constrained Equilibrium for the dimension reduction of kinetic schemes for a burner fed with a mixture of ethylene and air emulating MILD combustion conditions. A method based on the Computational Singular Perturbation theory is proposed for the identification of the species to be retained in the reduced representation of the chemistry. A significant reduction was achieved by using only 10 species (out of 34 species in the full kinetic scheme) and 3 elements; the results from the reduced model were in very good agreement with those of the full kinetic scheme. The sensitivity of predictions to the turbulence and combustion models was also preliminary assessed, indicating the need of modifying the residence time constant of the Eddy Dissipation Concept for MILD combustion conditions.
\end{abstract}

Keywords: flameless combustion, dimension reduction, Computational Fluid Dynamics, Computational Singular Perturbation

\section{Introduction}

MILD (Moderate or Intense Low-oxygen Dilution) combustion 1, also known as flameless combustion, ensures high combustion efficiencies with low pollutant emissions thanks to the dilution of reactants, usually achieved through recirculation of combustion products. The system is characterized by a more uniform temperature field than in traditional non-premixed combustion, and by the absence of high temperature peaks. The technology has been successfully applied in several processes and has been found to be able to handle a large variety of fuels, including low grade fuels [2], industrial by-products, hydrogen-enriched fuels [3 [4] [5] and biogas [6]. Further development of such technology would benefit of Computational Fluid Dynamics (CFD) tools. However, numerical modeling of MILD combustion is complicated by the strong coupling between turbulent mixing and chemical kinetics, indicated by a Damköhler number approaching unity, i.e. $D a \sim 1$ [7. As a result, the chemical mechanism describing oxidation in MILD conditions should be detailed, as proved by a large number of numerical investigations ([8] [9] [5] [10]); this leads to CPU-time demanding simulations when applied to burners and furnaces of practical interest, involving complex domains and heavy computational grids.

Hence, it is worthy to investigate whether a kinetic scheme can be reduced and to what extent, in order to preserve

${ }^{*}$ Corresponding author 
accuracy in MILD combustion calculations with lower CPU-time demand. Moreover the presence of diluent species may change the relevance of reaction paths; for instance Sabia et al. [11] showed how they act as third body species at low temperatures, while they interact with the $\mathrm{H}_{2} / \mathrm{O}_{2}$ branching chain at high temperatures.

Some useful works on MILD combustion burners fed with methane/hydrogen mixtures have been shown the suitability of reduced/skeletal schemes and the poor performance of others. For instance Aminian et al. [12] showed that the KEE58 skeletal mechanism [13] provided better predictions for a MILD burner fed with a $\mathrm{CH}_{4} / \mathrm{H}_{2}$ mixture with respect to the DRM19 mechanism [14], in accordance also with observations from 9]. However, no systematic study on the importance of the different chemical species has been carried out. Moreover, only few studies have focused on reduced kinetic schemes for fuels different that methane.

The present work aims at shedding light into the dimension reduction of the kinetic scheme for the simulation of an ethylene jet flame issuing in a hot coflow burner, emulating MILD combustion conditions, which has been fully characterized in literature by Medwell and Dally [15. This burner constitutes a strong asset for the validation of numerical models as it has been equipped with advanced diagnostics. For instance, experimental data on this burner fed with a mixture of methane and hydrogen, have been used by many researchers to validate turbulence/chemistry interaction models [8] [12, kinetic schemes [16 [9] [17, as well as the use of flamelet/progress variable approaches based on Large Eddy Simulations [18].

The main idea is to model the flame with a full detailed kinetic scheme and then extract the thermo-chemical field to analyse the characteristic time-scales associated with the evolution of the different chemical species. Then, an approach based on Computational Singular Perturbation is used to identify slow and fast species. The slow species will constitute the chemical species to be represented in the framework of a Rate-Controlled Constrained Equilibrium approach, for the reduction of kinetic scheme. Different reduced schemes, corresponding to different values of the threshold time-scale used to identify the slow species, will be implemented in a CFD model of the burner using the Eddy Dissipation Concept (EDC) combustion model. Moreover, the sensitivity of the CFD results to the Reynolds stresses closure and to EDC parameters will be also discussed.

\section{Test case}

The Adelaide Jet in Hot Coflow burner modeled in this work has been experimentally studied by Medwell and Dally [15] [19] and it is shown for sake of clarity in Figure 1 19.

It consists of a fuel jet nozzle, which has an inner diameter of $4.6 \mathrm{~mm}$, located at the center of a perforated disc in an annulus, with inner diameter of $82 \mathrm{~mm}$ and wall thickness of $2.8 \mathrm{~mm}$, which provides nearly uniform composition of hot oxidizer coflow to the reaction zone. The entire burner was placed inside a wind tunnel introducing room temperature air at the same velocity as the hot coflow. Table 1 shows the operating conditions for the investigated run, in which an ethylene/air mixture was fed in a hot coflow at $3 \%$ and $9 \% \mathrm{O}_{2}$ levels. The jet Reynolds number was around 10,000. The available data consist of the mean temperature, number concentration of $\mathrm{OH}$ and $\mathrm{CH}_{2} \mathrm{O}$ (the latter in arbitrary units) [15]. 


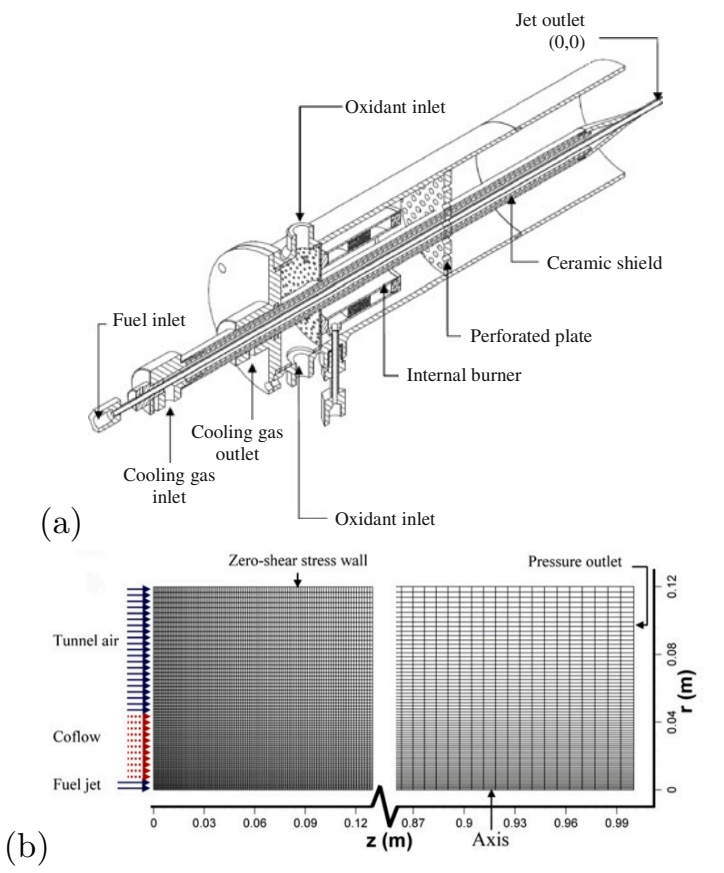

Figure 1: (a) Jet in Hot Coflow burner and (b) computational grid

Table 1: Experimental conditions for the $3 \% \mathrm{O}_{2} \mathrm{C}_{2} \mathrm{H}_{4}$ /air flame 19

\begin{tabular}{ccccc}
\hline \multicolumn{5}{c}{ Fuel } \\
\hline$U[\mathrm{~m} / \mathrm{s}]$ & $T[\mathrm{~K}]$ & $Y_{C 2 H 4}$ & $Y_{\text {air }}[-]$ \\
27.3 & 305 & 0.25 & 0.75 \\
\hline \multicolumn{5}{c}{ Coflow } \\
\hline$U[\mathrm{~m} / \mathrm{s}]$ & $T[\mathrm{~K}]$ & $Y_{O 2}[-]$ & $Y_{C O 2}[-]$ & $Y_{H 2 O}[-]$ \\
2.3 & 1100 & 0.03 & 0.03 & 0.10 \\
\hline
\end{tabular}




\section{Numerical model}

The geometry of the JHC burner allows the use of a 2D axisymmetric domain, constructed starting from the burner exit. The computational grid (25,200 cells) was chosen from a grid independence study base on Richardson extrapolation. A grid convergence index (GCI) below 5\% was obtained for both temperature and major species for the selected grid. Steady-state FANS equations were solved with a finite volume scheme using the commercial CFD code ANSYS FLUENT 16. Reynolds stresses were closed through the $\kappa-\varepsilon$ model with all standard constants, except for $C_{\varepsilon 1}$, which was set to 1.6 instead of 1.44 to compensate for the round-jet/plane-jet anomaly [20]. The results from this modified $\kappa-\varepsilon$ model were benchmarked to the ones of the standard $\kappa-\varepsilon$ model, the $\kappa-\varepsilon$ model with correction from Pope 21] (implemented in the code through a bespoke subroutine) and the $\kappa-\varepsilon /$ EASM (Explicit Algebraic Stress Model) [22. The interaction between turbulence and chemistry was treated with the Eddy Dissipation Concept model [23]; the model is appealing as it allows handling efficiently detailed kinetic schemes. However, in order to improve predictions, the fine structure residence time constant was modified from its standard value, $C_{\tau}=0.4083$, to $C_{\tau}=1.47$ and $C_{\tau}=3$, as suggested by [10, 24], and [25]. The volume fraction constant, $C_{\gamma}=2.1377$, was also modified to $C_{\gamma}=1.0$ in some simulations, to reduce temperature over-predictions at increasing axial distances [26].

A simulation with full detailed scheme was performed using the GRI3.0 mechanism [27] w/o NO reaction subset, resulting in 35 species (including nitrogen, hence 34 species to be transported) and 219 reversible reactions. Six more simulations were then performed using a Rate-Controlled Constrained Equilibrium reduction with a different number of chemical species, as will be described in the Results section. The Discrete Ordinate (DO) method together with the Weighted-Sum-of-Gray-Gases (WSGG) model with coefficients taken from Smith et al. 28, was employed to solve the radiative transfer equation (RTE) in 16 different directions across the computational domain. A pressure inlet/outlet conditions was adopted at the side boundary. Velocity inlets were specified for the fuel, coflow and air inlets. The turbulence levels of the fuel jet and the coflow were set to $16 \%[29$ and $11.55 \%$ [30, respectively. A second order discretization scheme was employed for all equations and the pressure-velocity coupling was solved with the SIMPLE algorithm.

\section{Dimension reduction}

Dimension reduction of the kinetic scheme was performed through the Rate-Controlled Constrained Equilibrium (RCCE) [31]. In RCCE, transport equations are solved for a smaller number of species $n_{r s}$ (represented species or constraints, i.e. slow species) than the total number of species $n_{s}$ in the full chemical mechanism. The thermochemical state of the remaining species (unrepresented species, i.e. fast species) is then constrained by the leading species, and it is reconstructed through the assumption of chemical equilibrium. This requires knowledge of the elements in the unrepresented species, so that the reduced kinetic representation basically consists of $n_{r s}$ species and $n_{e}$ elements. The accuracy of the method is largely dependent on the choice of the constraints [32]. For instance Hiremath et al. 33. 34 suggested a greedy algorithm to select the represented species, based on the minimization of the reaction mapping error.

In the present work, the selection of constraints is made through the Computational Singular Perturbation method developed by Lam and Goussis [35. According to this theory, a general chemical reaction system that contains $R$ 
elementary chemical reactions and $N$ species, can be expressed as:

$$
\mathbf{g}(\mathbf{y})=\frac{d \mathbf{y}}{d t},
$$

where $\mathbf{y}$ is the $N x 1$ concentration vector of all the species, $\mathrm{S}$ is the $N x R$ stoichiometric coefficient matrix and $\mathbf{g}(\mathbf{y})$ is the $R x 1$ species production rates vector of the elementary reactions. By taking the time derivative of Eq. (1), one obtains:

$$
\frac{d \mathbf{g}}{d t}=\mathbf{J} \cdot \mathbf{g}
$$

and

$$
\mathbf{J}=\frac{d \mathbf{g}}{d y}
$$

where $\mathbf{J}$ is the Jacobian matrix, depending only on the state of reaction system. An eigenvalue decomposition of $\mathbf{J}$ gives:

$$
\mathbf{J}=\mathbf{A L A}^{-1}
$$

where $\mathbf{A}$ is the matrix of the basis vectors (eigenvectors). $\mathbf{L}$ is the diagonal matrix, whose elements are the eigenvalues $\lambda$ of $\mathbf{J}$. The original system can be then projected to obtain the equation for the modes $\mathbf{f}=\mathbf{A}^{-1} \cdot \mathbf{g}$, which is:

$$
\frac{d \mathbf{f}}{d t}=\mathbf{L} \cdot \mathbf{f}
$$

whose solution is

$$
f_{i}=e^{-\lambda_{i} t}
$$

Then, a time scale separation can be performed by identifying fast and slow modes, as:

$$
\mathbf{A}=\left[\begin{array}{ll}
\mathbf{A}_{i, f a s t} & \mathbf{A}_{i, \text { slow }}
\end{array}\right]
$$

so that the time derivatives of the $i$-th species mass fraction $y_{i}$ are

$$
\frac{d y_{i}}{d t}=g_{i}=\mathbf{a}_{i} \cdot \mathbf{f}=\mathbf{a}_{i, f a s t} \cdot \mathbf{f}_{\text {fast }}+\mathbf{a}_{\text {slow }} \cdot \mathbf{f}_{i, s l o w}
$$

If $\mathbf{a}_{i, s l o w} \approx 0$ then

$$
\frac{d y_{i}}{d t} \approx \mathbf{a}_{i, f a s t} \cdot \mathbf{f}_{\text {fast }} \approx 0
$$

and the species be can be regarded at equilibrium; hence it will be disregarded in the RCCE reduction.

As we basically want to provide a proof of concept, the selection was carried out on the results obtained with the full kinetic scheme, even though a selection via canonical reactors with operating conditions similar to the case to be investigated, is also feasible. Hence the procedure consisted in: collecting the thermo-chemical data from predictions with a detailed kinetic scheme conditioned at the stoichiometric mixture fraction; evaluating the Jacobian matrix $\mathbf{J}$; performing the eigenvalue decomposition of $\mathbf{J}$; choosing the cutoff time-scale; identifying the constraints and finally performing the RCCE simulations. The Jacobian matrix is evaluated through the in-house Matlab JACOBEN code, which is described in detail in [7]. The code is particularly interesting as it formulates the chemical source term equations as symbolic expressions and then uses the symbolic differentiation function in MATLAB to form the analytical expressions for the derivatives of the chemical source terms with respect to chemical species. The code requires the input of a chemical mechanism in CHEMKIN format, and a thermo-chemical state space (i.e. species 
(a)

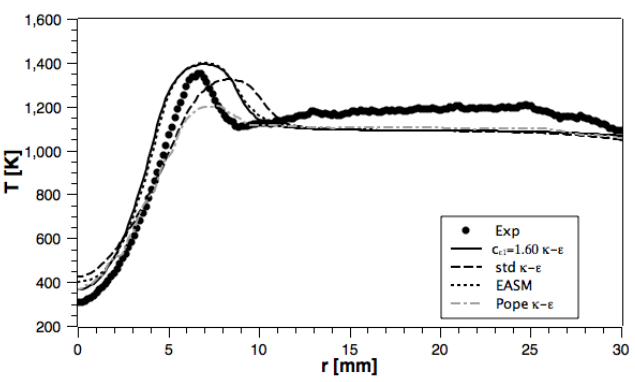

(b)

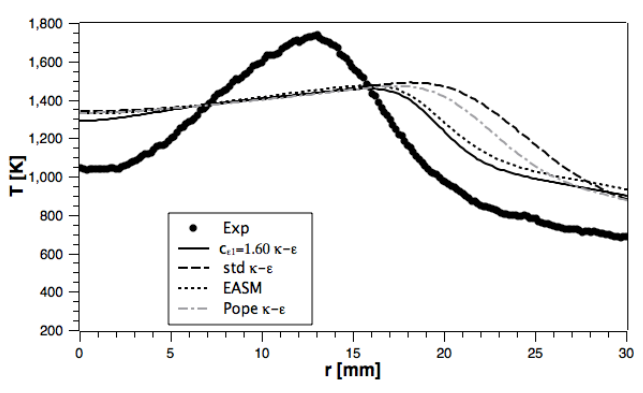

Figure 2: Comparison of experimental radial profiles of temperature, and those predicted with different turbulence models at (a) (a) $z=35 \mathrm{~mm}$ and (b) $z=125 \mathrm{~mm} .3 \% \mathrm{O}_{2}$ case. Full mechanism, $C_{\tau}=1.47$ and $C_{\gamma}=2.1377$

mass fractions and temperature). A Jacobian matrix is then evaluated for every observation provided in the thermochemical state. The $\mathbf{L}$ matrix from the eigenvalue decomposition of $\mathbf{J}$ contains the eigenvalues, which represent the inverse of the chemical timescales.

$$
\tau_{i}=\frac{1}{\left|\lambda_{i}\right|}
$$

Once a cutoff time-scale is chosen to distinguish between slow and fast species, the eigenvectors are analyzed to identify the species for which the corresponding eigenvectors are negligible (below 0.01). Once the species are identified, they are set as constraints for the dimension reduction via RCCE. A sensitivity analysis was carried out, to investigate the effect of various cutoff time-scales, in the range $\tau=6.5 \cdot 10^{-6}-1.89 \cdot 10^{-4} \mathrm{~s}$, on the results. The choice of the cutoff time-scale has a direct effect on the number of constraints and unrepresented species, as indicated in Table 2 that will be discussed in the Results section.

\section{Results}

A preliminary investigation of the effect of different closure models was carried out using the full kinetic mechanism.

As for the turbulence model, radial temperature profiles at $z=35 \mathrm{~mm}$, shown in Figure $2 \mathrm{p}$, indicate that the standard $\kappa-\varepsilon$ model predicts a temperature peak located at larger radial distance than that measured experimentally. This is in agreement with the well known overestimation of the jet spread and decay provided by the standard $\kappa-\varepsilon$ turbulence model. The position of the peak is better captured by EASM, the $\kappa-\varepsilon$ model with $C_{\varepsilon 1}=1.6$ and the Pope [21] $\kappa-\varepsilon$ model, even though the latter model underestimates the value of the temperature peak. The profiles at $z=125 \mathrm{~mm}$ show larger discrepancies for all turbulence models. Similar discrepancies were also reported by [36], with different turbulent models and they were partly explained by an inaccurate knowledge of the inlet condition 
(a)
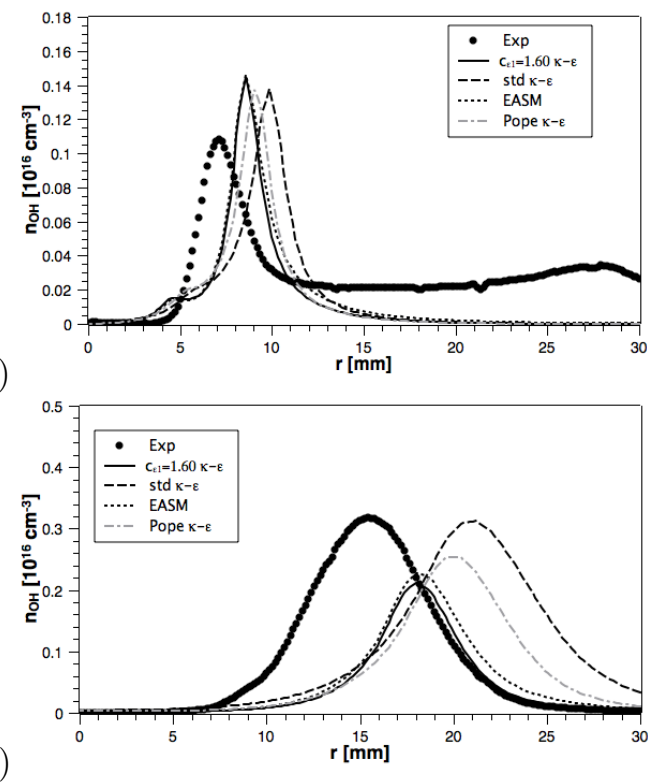

Figure 3: Comparison of experimental radial profiles of $\mathrm{OH}$ number density, and those predicted with different turbulence models at (a) $z=35 \mathrm{~mm}$ and (b) $z=125 \mathrm{~mm} .3 \% \mathrm{O}_{2}$ case. Full mechanism, $C_{\tau}=1.47$ and $C_{\gamma}=2.1377$

for the coflow stream. At $z=125 \mathrm{~mm}$, the surrounding air begins to mix with the jet and coflow; so potential improvements may be achieved by modifying the mixing through adjustment of the air inlet turbulence levels in RANS approaches [10] or by applying LES models. Other works in literature concentrate on the profiles at $z=35$ $\mathrm{mm}$ [26]. Similar observations may be drawn from the profiles of $\mathrm{OH}$ reported in Figure 3 for instance the position of $\mathrm{OH}$ peak at $z=35 \mathrm{~mm}$ is shifted towards larger radial distances than the measured one, especially for the standard $\kappa-\varepsilon$ model.

Figure 4 a shows the effect of the EDC residence time constant $C_{\tau}$ on temperature and $\mathrm{OH}$ number density profiles at $z=35 \mathrm{~mm}$ : increasing the constant leads to a decrease of both temperature and $\mathrm{OH}$ peaks. The experimental temperature peak value is well matched by $C_{\tau}=3$ that hence will be used for the dimension reduction analysis. The original EDC model (i.e. $C_{\tau}=0.41$ ) largely over-estimates the $\mathrm{OH}$ levels, whereas better agreement is obtained by increasing $C_{\tau}$. Similar observations can be made from the comparison of experimental and predicted temperature and $\mathrm{OH}$ radial profiles at $z=125 \mathrm{~mm}$. This results are in agreement with the observations made in [12, 24] and [25] for a jet in hot coflow fed with mixture of $\mathrm{CH}_{4} / \mathrm{H}_{4}$ and natural gas, respectively.

The dimension reduction was performed using different threshold time-scales in the range $\tau=6.5 \cdot 10^{-6}-1.89 \cdot 10^{-4}$ $\mathrm{s}$, to separate slow and fast chemical species. Table 2 lists, for each time-scale, the species that were disregarded and selected for be set at equilibrium, since they are characterized by almost zero coefficients $\left(a_{i}<0.01\right)$ on the eigenvectors associated to the time scales targeted as slow (Eq. 9p). Choosing a larger cut-off shifts the constraint selection towards slower scales, thus leading to a higher number of unrepresented species. In particular using a timescale threshold of $6.56 \cdot 10^{-6} \mathrm{~s}$ (reduction R6) leads to 10 species to be disregarded, hence $n_{r s}=24$. Consequently, the reaction space is described by $n_{r s}=24$ species and $n_{e}=3$ elements (i.e., C, $\mathrm{H}$ and O). Setting the threshold to larger values, i.e. $\tau=1.89 \cdot 10^{-4} \mathrm{~s}$ leads to 24 species to be unrepresented (see R1 reduction); this allows a significant decrease of the CPU time, as just $n_{r s}=10$ should be transported along with $n_{e}=3$ elements, instead of 
(a)

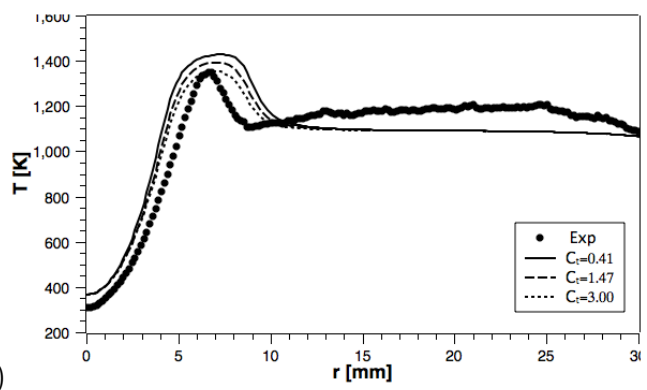

(b)

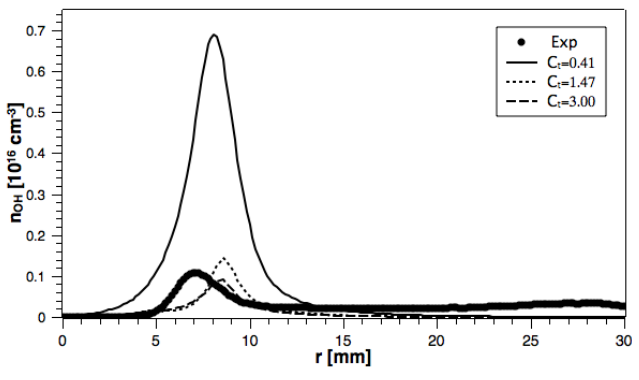

Figure 4: Comparison of experimental radial profiles of (a) temperature and (b) OH number density and those predicted with different EDC residence time constants at $z=35 \mathrm{~mm} .3 \% \mathrm{O}_{2}$ case. Full mechanism, $C_{\gamma}=2.1377, \kappa-\varepsilon$ with $c_{\varepsilon 1}=1.6$.

transporting $n_{s}=34$ chemical species of the full mechanism.

The predictions achieved with the different dimension reductions are compared with those of the full mechanism in Figure 5 and Figure 6 for temperature and $\mathrm{OH}$ concentration, respectively.

The differences between temperature profiles at $z=35 \mathrm{~mm}$ obtained with the full scheme and the R1 (i.e. the largest) reduction are not noticeable. The $\mathrm{OH}$ levels at the same locations show some differences in the peak value, with the $\mathrm{R} 1$ reduction providing a peak about $10 \%$ larger that predicted with the full scheme. However such difference may be considered acceptable given the strong reduction of the number of transported species. Some effects on the temperature profiles can be observed at $z=125 \mathrm{~mm}$ near the burner axis, where the $\mathrm{R} 1$ scheme underestimates the temperature with respect to the full mechanism. The R3 scheme, with 19 disregarded species, provides only a small temperature under-prediction. Conversely, no significant differences between the models can be observed from the $\mathrm{OH}$ profiles at $z=125 \mathrm{~mm}$. Figure 7 shows the comparison between radial profiles of formaldehyde and carbon monoxide at $z=35 \mathrm{~mm}$, predicted with the full scheme and those obtained with different thresholds for the RCCE reduction. For the $\mathrm{CH}_{2} \mathrm{O}$ a very good agreement between the full scheme and all reduction levels is observed; for the $\mathrm{CO}$, some under-prediction of the peak levels is noticed in case of the largest reduction (i.e. R1 and R2), but results well match the full scheme predictions up to the $\mathrm{R} 3$ reduction.

The contours of $\mathrm{C}, \mathrm{H}$ and $\mathrm{O}$ elements in the unrepresented species are shown in Figure 8 for the $\mathrm{R} 1$ reduction. The elements are confined to the flame region and they are very small in quantity, being their maximum values lower then 0.01. This observation is in agreement with the RCCE simulations of a buff-body-stabilized non premixed burner by [32, who used a different method for selecting the constraints. The R6 reduction leaded to a mass fraction of the unrepresented elements about ten times smaller, i.e. lower than 0.001 .

The effect of the of coflow composition on the RCCE reduction was finally assessed. The same reduction obtained for the 3\% case was used for the $9 \%$ dilution case, and shown in Figure 9 . The simulations were performed with 
Table 2: Threshold time-scale and unrepresented species for different dimension reductions.

\begin{tabular}{|c|c|c|c|}
\hline Cases & $\tau[\mathrm{s}]$ & $n_{r s}[-]$ & Unrepresented species \\
\hline $\mathrm{R} 1$ & $1.89 \cdot 10^{-4}$ & 10 & $\begin{array}{c}\mathrm{HO}_{2}, \mathrm{H}_{2} \mathrm{O}_{2}, \mathrm{C}, \mathrm{CH}, \mathrm{CH}_{2}, \mathrm{CH}_{2}<\mathrm{s}>, \mathrm{CH}_{3}, \mathrm{HCO}, \mathrm{CH}_{2} \mathrm{O}, \mathrm{CH}_{2} \mathrm{OH}, \mathrm{CH}_{3} \mathrm{O} \\
\mathrm{CH}_{3} \mathrm{OH}, \mathrm{C}_{2} \mathrm{H}, \mathrm{C}_{2} \mathrm{H}_{3}, \mathrm{C}_{2} \mathrm{H} 5, \mathrm{C}_{2} \mathrm{H}_{6}, \mathrm{HCCO}, \mathrm{CH}_{2} \mathrm{CO}, \mathrm{HCCOH}, \mathrm{C}_{3} \mathrm{H}_{7}, \mathrm{C}_{3} \mathrm{H}_{8}, \\
\mathrm{CH}_{2} \mathrm{CHO}, \mathrm{CH}_{3} \mathrm{CHO}\end{array}$ \\
\hline $\mathrm{R} 2$ & $6.75 \cdot 10^{-5}$ & 12 & $\begin{array}{c}\mathrm{O}, \mathrm{HO}_{2}, \mathrm{H}_{2} \mathrm{O}_{2}, \mathrm{C}, \mathrm{CH}, \mathrm{CH}_{2}, \mathrm{CH}_{2}<\mathrm{s}>, \mathrm{HCO}, \mathrm{CH}_{2} \mathrm{O}, \mathrm{CH}_{2} \mathrm{OH}, \mathrm{CH}_{3} \mathrm{O}, \\
\mathrm{CH}_{3} \mathrm{OH}, \mathrm{C}_{2} \mathrm{H}, \mathrm{C}_{2} \mathrm{H}_{3}, \mathrm{C}_{2} \mathrm{H} 5, \mathrm{C}_{2} \mathrm{H}_{6}, \mathrm{HCCO}, \mathrm{HCCOH}, \mathrm{C}_{3} \mathrm{H}_{7}, \mathrm{C}_{3} \mathrm{H}_{8}, \mathrm{CH}_{2} \mathrm{CHO}, \\
\mathrm{CH}_{3} \mathrm{CHO},\end{array}$ \\
\hline $\mathrm{R} 3$ & $3.24 \cdot 10^{-5}$ & 13 & $\begin{array}{c}\mathrm{H}_{2} \mathrm{O}_{2}, \mathrm{C}, \mathrm{CH}, \mathrm{CH}_{2}, \mathrm{CH}_{2}<\mathrm{s}>, \mathrm{HCO}, \mathrm{CH}_{2} \mathrm{OH}, \mathrm{CH}_{3} \mathrm{O}, \mathrm{C}_{2} \mathrm{H}, \mathrm{C}_{2} \mathrm{H}_{3}, \mathrm{C}_{2} \mathrm{H} 5, \\
\mathrm{C}_{3} \mathrm{H}_{7}, \mathrm{C}_{3} \mathrm{H}_{8}, \mathrm{CH}_{2} \mathrm{CHO}\end{array}$ \\
\hline $\mathrm{R} 4$ & $1.98 \cdot 10^{-5}$ & 15 & $\begin{array}{c}\mathrm{HO}_{2}, \mathrm{H}_{2} \mathrm{O}_{2}, \mathrm{C}, \mathrm{CH}, \mathrm{CH}_{2}, \mathrm{CH}_{2}<\mathrm{s}>, \mathrm{HCO}, \mathrm{CH}_{2} \mathrm{OH}, \mathrm{CH}_{3} \mathrm{O}, \mathrm{CH}_{3} \mathrm{OH}, \mathrm{C}_{2} \mathrm{H} \\
\mathrm{C}_{2} \mathrm{H}_{3}, \mathrm{C}_{2} \mathrm{H} 5, \mathrm{C}_{2} \mathrm{H}_{6}, \mathrm{HCCOH}, \mathrm{C}_{3} \mathrm{H}_{7}, \mathrm{C}_{3} \mathrm{H}_{8}, \mathrm{CH}_{2} \mathrm{CHO}, \mathrm{CH}_{3} \mathrm{CHO}\end{array}$ \\
\hline $\mathrm{R} 5$ & $7.59 \cdot 10^{-6}$ & 20 & $\begin{array}{c}\mathrm{H}_{2} \mathrm{O}_{2}, \mathrm{C}, \mathrm{CH}, \mathrm{CH}_{2}, \mathrm{CH}_{2}<\mathrm{s}>, \mathrm{HCO}, \mathrm{CH}_{2} \mathrm{OH}, \mathrm{CH}_{3} \mathrm{O}, \mathrm{C}_{2} \mathrm{H}, \mathrm{C}_{2} \mathrm{H}_{3}, \mathrm{C}_{2} \mathrm{H}_{5}, \\
\mathrm{C}_{3} \mathrm{H}_{7}, \mathrm{C}_{3} \mathrm{H}_{8}, \mathrm{CH}_{2} \mathrm{CHO},\end{array}$ \\
\hline R6 & $6.57 \cdot 10^{-6}$ & 24 & $\mathrm{H}_{2} \mathrm{O}_{2}, \mathrm{C}, \mathrm{CH}, \mathrm{CH}_{2}<s>, \mathrm{CH}_{2} \mathrm{OH}, \mathrm{CH}_{3} \mathrm{O}, \mathrm{C}_{2} \mathrm{H}, \mathrm{C}_{2} \mathrm{H}_{3}, \mathrm{C}_{3} \mathrm{H}_{7}, \mathrm{CH}_{2} \mathrm{CHO}$ \\
\hline
\end{tabular}

(a)

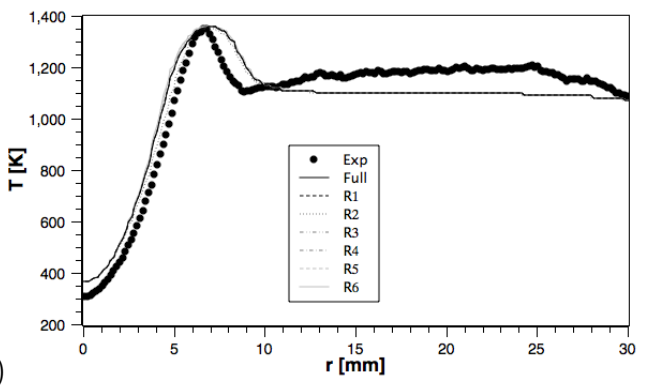

(b)

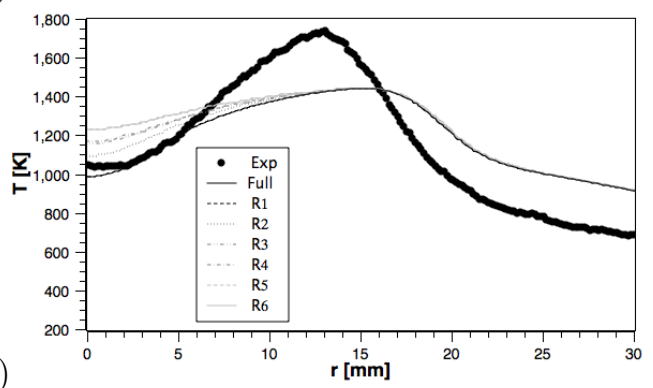

Figure 5: Comparison of experimental radial profiles of temperature and those predicted with the full kinetic scheme and different RCCE reductions at (a) $z=35 \mathrm{~mm}$ and (b) $z=125 \mathrm{~mm} .3 \% \mathrm{O}_{2}$ case. $C_{\tau}=3$ and $C_{\gamma}=2.1377, \kappa-\varepsilon$ with $c_{\varepsilon 1}=1.6$. 


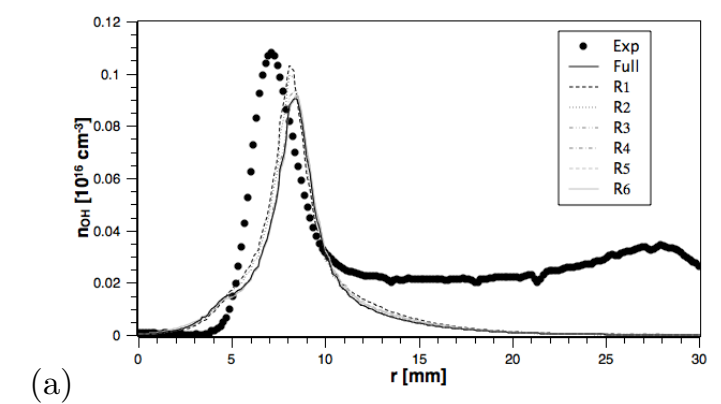

(a)

(b)

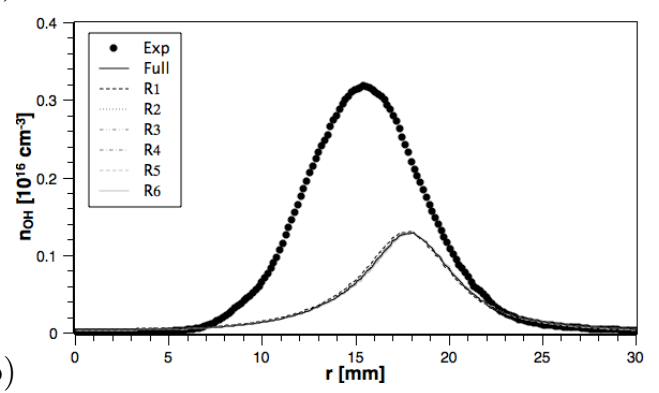

Figure 6: Comparison of experimental radial profiles of $\mathrm{OH}$ number density and those predicted with the full kinetic scheme and different RCCE reductions at (a) $z=35 \mathrm{~mm}$ and (b) $z=125 \mathrm{~mm} .3 \% \mathrm{O}_{2}$ case. $C_{\tau}=3$ and $C_{\gamma}=2.1377, \kappa-\varepsilon$ with $c_{\varepsilon 1}=1.6$.

the same settings as the previous ones, except for the value of $C_{\gamma}$, which was set to 1 as suggested by [26]. This helps improving the temperature predictions, without affecting the impact of the RCCE reduction. While the $\mathrm{O}_{2}$ dilution level significantly affects the temperature and species fields, the application of the set of species defined by the reduction R1 (Table 2) appears well suited for the $9 \%$ case, at both $z=35 \mathrm{~mm}$ and $z=125 \mathrm{~mm}$. Minor differences are observed for temperature, while for $\mathrm{OH}$ they are comparable to what is observed for the $3 \%$ case.

\section{Conclusions}

Rate-Controlled Constrained Equilibrium dimension reduction has been investigated for MILD combustion. The species to be represented (constraints) were chosen on the basis of data conditioned at the stoichiometric mixture fraction obtained from simulations with a detailed scheme, using a simplified approach based on Computational Singular Perturbation theory for separating slow and fast species. The proposed approach is able to correctly distinguish between fast and slow chemical species, providing an effective tool for the reduction of the number of species transport equations. For the Jet in Hot Coflow burner investigated in the present paper, the RCCE reduction was found to provide a good agreement with the full chemistry predictions, even when disregarding 24 species on a total of 34 in the full scheme. The mass fraction of the elements in the unrepresented species was found to be always less than $1 \%$ and restricted to the flame region. The same reduction obtained for the $3 \%$ case was able to successfully predict the behaviour for the $9 \%$ dilution case. The proposed methodology for time-scale separation appears very appealing for the simulation of combustion regimes, such as MILD combustion, where turbulencechemistry interactions are very strong and, consequently, the role of chemical kinetics is significant.

\section{References}

[1] A. Cavaliere, M. de Joannon, Prog Energy Combust Sci 30 (2004) 329-366. 


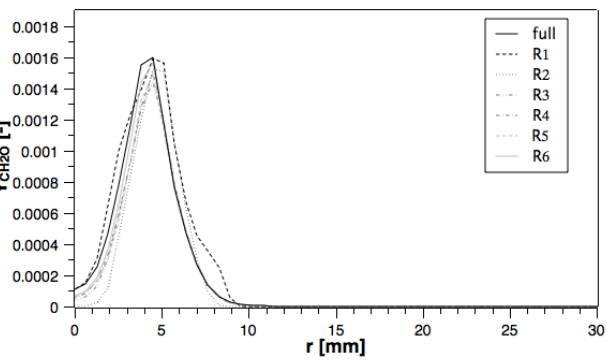

(a)

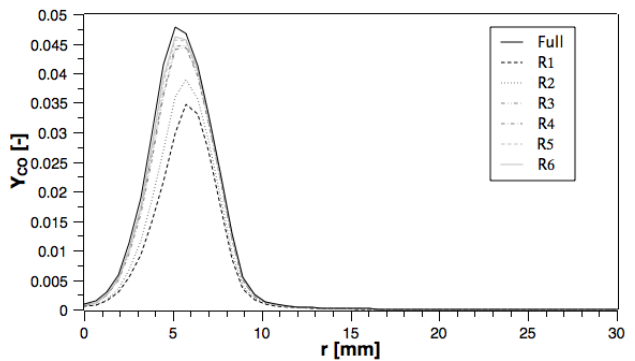

(b)

Figure 7: Comparison of radial profiles of $\mathrm{CH}_{2} \mathrm{O}$ and $\mathrm{CO}$ at $z=35 \mathrm{~mm}$ as predicted with the full kinetic scheme and those obtained with different RCCE reductions. $3 \% \mathrm{O}_{2}$ case. $C_{\tau}=3$ and $C_{\gamma}=2.1377, \kappa-\varepsilon$ with $c_{\varepsilon 1}=1.6$.

(a)
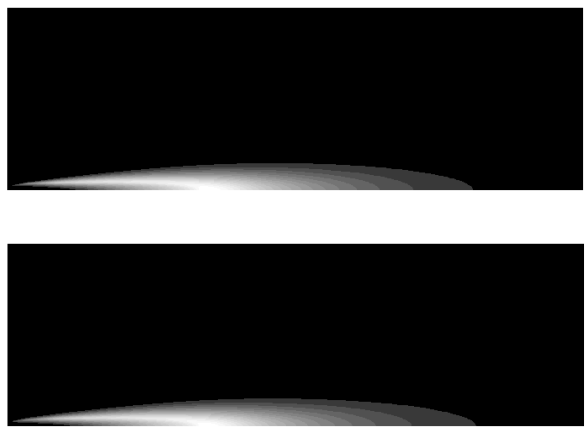

(b)

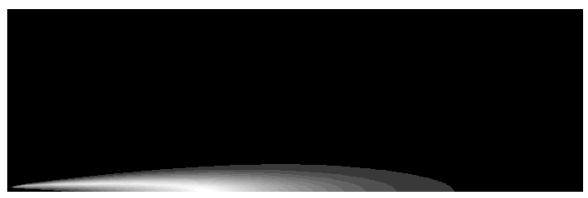

(c)

Figure 8: Distribution of mass fractions of unrepresented elements for R1 reduction:(a) C; (b) H; (c) O. Black color corresponds to zero whereas the white color to (a) $9.9 \cdot 10^{-3} ; 1.1 \cdot 10^{-3}$; (c) $5.8 \cdot 10^{-3}$. 


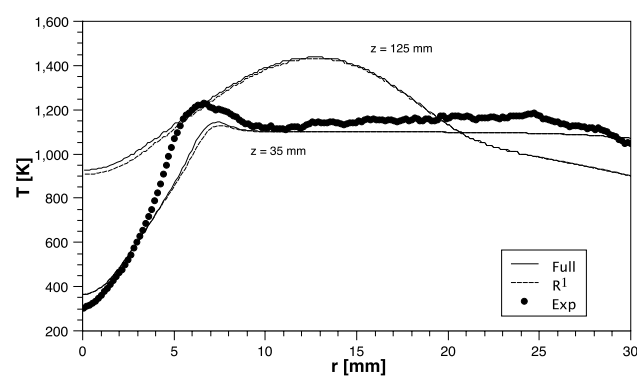

(a)

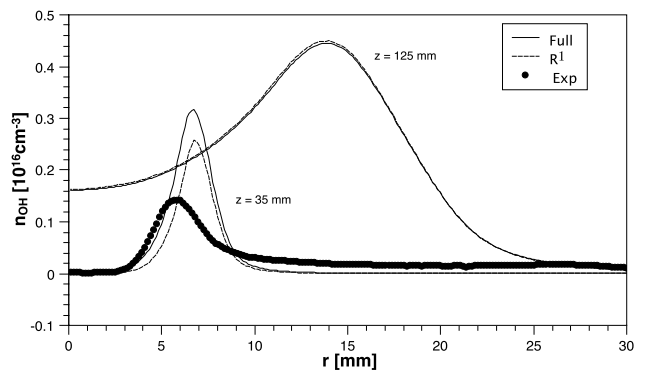

(b)

Figure 9: Comparison of experimental and numerical radial profiles of (a) temperature and (b) OH number density, and those predicted with the full kinetic scheme and the R1 reduction at $z=35 \mathrm{~mm}$ and $z=125 \mathrm{~mm} .9 \% \mathrm{O}_{2}$ case. $C_{\tau}=3$ and $C_{\gamma}=1.0, \kappa-\varepsilon$ with $c_{\varepsilon 1}=1.6$. Experimental data are not available at $z=125 \mathrm{~mm}$

[2] G.-M. Choi, M. Katsuki, Energy Convers Manag 42 (2001) 639 - 652.

[3] M. Derudi, A. Villani, R. Rota, Proc Combust Inst 31 (2007) 3393 - 3400.

[4] C. Galletti, A. Parente, L. Tognotti, Combust Flame 151 (2007) 649 - 664.

[5] C. Galletti, A. Parente, M. Derudi, R. Rota, L. Tognotti, Int J Hydrog Energy 34 (2009) 8339 - 8351.

[6] S. Chen, C. Zheng, Int J Hydrog Energy 36 (2011) 15403 - 15413.

[7] B. J. Isaac, A. Parente, C. Galletti, J. N. Thornock, P. J. Smith, L. Tognotti, Energy Fuels 27 (2013) 2255 2265.

[8] F. Christo, B. Dally, Combust Flame 142 (2005) 117 - 129.

[9] A. Parente, C. Galletti, L. Tognotti, Int J Hydrog Energy 33 (2008) 7553 - 7564.

[10] J. Aminian, C. Galletti, S. Shahhosseini, L. Tognotti, Appl Therm Eng 31 (2011) 3287 - 3300.

[11] P. Sabia, M. Lubrano Lavadera, G. Sorrentino, P. Giudicianni, R. Ragucci, M. de Joannon, Flow, Turbulence and Combustion (2015) 1-16.

[12] J. Aminian, C. Galletti, S. Shahhosseini, L. Tognotti, Flow, Turbulence and Combustion 88 (2012) 597-623.

[13] S. H. Bilger, R. W. Starner, R. Kee, Combustion and Flame 80 (1990) 135-149. 
[14] A. Kazakov, M. Frenklach, available at http://combustion.berkeley.edu/drm/ (????).

[15] P. R. Medwell, B. B. Dally, Combust Flame 159 (2012) 3138 - 3145.

[16] F. Wang, J. Mi, P. Li, C. Zheng, Int J Hydrog Energy 36 (2011) 9267 - 9277.

[17] A. Mardani, S. Tabejamaat, S. Hassanpour, Combust Flame 160 (2013) 1636 - 1649.

[18] M. Ihme, Y. C. See, Proc Combust Inst 33 (2011) 1309 - 1317.

[19] P. R. Medwell, P. A. Kalt, B. B. Dally, Combust Flame 152 (2008) 100 - 113.

[20] A. P. Morse, Axisymmetric Turbulent Shear Flows with and without Swirl, Ph.D. thesis, London University, 1977.

[21] S. B. Pope, American Institute of Aeronautics and Astronautics Journal 16 (1978) 279 - 281.

[22] T. Gatski, C. Speziale, Journal of Fluid Mechanics 254 (1993) 59-78.

[23] B. F. Magnussen, in: ECCOMAS Thematic Conference on Computational Combustion, Lisbon, June 21-24, 2005.

[24] A. Parente, M. R. Malik, F. Contino, A. Cuoci, B. B. Dally, Fuel 163 (2016) $98-111$.

[25] A. De, E. Oldenhof, P. Sathiah, D. Roekaerts, Flow, Turbulence and Combustion 87 (2011) 537-567.

[26] M. Evans, P. Medwell, Z. Tian, Combustion Science and Technology 187 (2015) 1093-1109.

[27] G. Smith, D. Golden, M. Frenklach, N. Moriarty, B. Eiteneer, M. Goldenberg, C. Bowman, R. Hanson, S. Song, W. Gardiner Jr, et al. (1999).

[28] T. Smith, Z. Shen, J. N. Friedman, J Heat Transf 104 (1982) $602-608$.

[29] F. C. Christo, B. B. Dally, Combust Flame 142 (2005) 117-129.

[30] A. Frassoldati, P. Sharma, A. Cuoci, T. Faravelli, E. Ranzi, Appl Therm Eng 30 (2010) 376 - 383.

[31] J. C. Keck, Progress in Energy and Combustion Science 16 (1990) 125 - 154.

[32] Z. Ren, G. M. Goldin, V. Hiremath, S. B. Pope, Fuel 105 (2013) $636-644$.

[33] V. Hiremath, S. R. Lantz, H. Wang, S. B. Pope, Combustion and Flame 159 (2012) 3096 - 3109.

[34] V. Hiremath, Z. Ren, S. Pope, Combustion Theory and Modelling 14 (2010) 619-652.

[35] S. H. Lam, D. A. Goussis, International Journal of Chemical Kinetics 26 (1994) 461-486.

[36] S. R. Shabanian, P. R. Medwell, M. Rahimi, A. Frassoldati, A. Cuoci, Appl Therm Eng 52 (2013) 538 - 554. 